\title{
Use of Internet of Things With Data Prediction on Healthcare Environments:
}

\section{A Survey}

\author{
Gabriel Souto Fischer, Universidade do Vale do Rio dos Sinos - Unisinos, São Leopoldo, Brazil \\ Rodrigo da Rosa Righi, Universidade do Vale do Rio dos Sinos - Unisinos, São Leopoldo Brazil \\ Vinicius Facco Rodrigues, Universidade do Vale do Rio dos Sinos - Unisinos, São Leopoldo, Brazil \\ (iD) https://orcid.org/0000-0001-6129-0548 \\ Cristiano André da Costa, Universidade do Vale do Rio dos Sinos - Unisinos, São Leopoldo, Brazil
}

\begin{abstract}
Internet of Things (IoT) is a constantly growing paradigm that promises to revolutionize healthcare applications and could be associated with several other techniques. Data prediction is another widely used paradigm, where data captured over time is analyzed in order to identify and predict problematic situations that may happen in the future. After research, no surveys that address IoT combined with data prediction in healthcare area exist in the literature. In this context, this work presents a systematic literature review on Internet of Things applied to healthcare area with a focus on data prediction, presenting twenty-three papers about this theme as results, as well as a comparative analysis between them. The main contribution for literature is a taxonomy for IoT systems with data prediction applied to healthcare. Finally, this article presents the possibilities and challenges of exploration in the study area, showing the existing gaps for future approaches.
\end{abstract}

\section{KEYWORDS}

Data Prediction, Distributed Systems, Health, Healthcare Environments, Internet of Things, Sensors, Survey, Taxonomy

\section{INTRODUCTION}

Internet of Things (IoT) is a computational concept where physical objects and "things" are connected through a network structure and are part of the internet activities in order to exchange information about themselves and about objects and things around themselves (Singh \& Kapoor, 2017). The development of this paradigm is in constant growth because of the continuous efforts of the research community since IoT allows unlimited applications to solve unlimited needs in all spheres of life. Thus, in a not-so-distant future, everything in our homes, workplaces, and study will have a unique internet address and, through the network, it will be possible to monitor and control any of our "things" (Singh \& Kapoor, 2017). According to Sarhan (2018), IoT is used in various domains, such starting on January 25, 2021 in the gold Open Access journal, International Journal of E-Health and Medical Communications (converted to gold Open Access January 1, 2021), and will be distributed under the terms of the Creative Commons Attribution License (http://creativecommons.org/licenses/by/4.0/) which permits unrestricted use, distribution, and production in any medium, provided the author of the original work and original publication source are properly credited. 
as airports, military, and healthcare. IoT enables the devices to interact not only with each other but with services and people on a global scale (Akeju, Butakov, \& Aghili, 2018). The world is undergoing an unprecedented technological transformation that evolves isolated systems to ubiquitous internetenabled "things" capable of generating and exchanging large amounts of valuable data. The IoT is a new reality that is completely changing everyday life. In addition, it also promises to revolutionize healthcare applications, enabling a more personalized, preventive and collaborative way of caring for patients (Pinto, Cabral, \& Gomes, 2017).

According to Senthilkumar, Manikandan, Devi and Lokesh (2018), IoT remote health monitoring systems have advantages over traditional health monitoring systems. Patients can use health sensors 24 hours a day for monitoring. A nurse or doctor can observe a patient for a limited time by day, but critical health issues can occur at any moment. Based on this, 24/7 monitoring of health facts is crucial, and it is necessary. In this context, IoT assisted patients can be accessed for medical staff over the internet and by other systems, the health state of a patient can be supervised uninterruptedly, being possible to detect health risk situations at the right time, in order to be possible to apply the appropriate countermeasures. Also, IoT can support to collect health records that can be used to generate statistic information correlated to a health condition. Using these statistics, surveillance and risk drawing of diseases can be completed using remote health data. According to Singh (2018), using IoT, systems are able to analyze and predict health disorders in early stage through Data Prediction techniques applied to generated data.

There are people who, when they have a health problem, can make an appointment in a clinic with a doctor they trust. Other people decide to go to the most appropriate hospital for their needs. In other cases, the health situation is so critical that the only alternative is to go as quickly as possible to hospital care. Thus, hospitals and healthcare environments are extremely important service points for the general population to perform one of the most important tasks: to ensure medical treatment. There are many environments, resources and processes within a hospital to accomplish this task. Thus, it becomes interesting to have effective control over how these resources and processes are being used and executed in order to identify optimization points. This becomes even more necessary when it comes across the Brazilian reality, where hospitals are increasingly crowded with people to attend. When a hospital or emergency care unit is opened, usually it takes a long time until it exceeds its service capacity. If it were possible to identify when the points of care and resources would have a demand higher than their ability to attend, it would be possible to establish action plans to minimize or perhaps even eliminate these bottlenecks in the healthcare environments systems. However, how can one analyze and define when this moment is about to arrive? Relying only on the judgment of people who work with these resources, with no efficient way of recording their uses, and no statistically reliable prediction system can become a problem, with a high probability of errors in their evaluation.

In this context, in order to identify the state of the art for IoT systems with Data Prediction applied to healthcare and to discuss the main open issues, this work surveys the main contributions of the scientific community over the last years. The main objective of this work is to review the use of Internet of Things combined with Data Prediction in healthcare literature and describe the existing models. As a way of mapping this study scenario, we used the systematic literature review methodology to choose the studies (Roehrs, Costa, Righi, \& Oliveira, 2017). As a result, were reviewed scientific studies published in the last years, selected the most significant approaches, and thoroughly surveyed the use of IoT combined with Data Prediction in the healthcare field. Also, was developed an updated and wide taxonomy for IoT systems with Data Prediction applied to healthcare and indicated challenges and possibilities for future study. Contributions were also proposed in the field from the study of related works, which are an updated taxonomy and an updated vision about main challenges and possibilities about the use of IoT with Data Prediction applied to healthcare.

This article is organized as follows: Section 2 presents the background, bringing other surveys in this scenario, and gaps in their approaches. Section 3 presents the article selection process through a systematic literature review for Health IoT systems, bringing a comparison between the selected 
studies. Section 4 presents the state of the art for the Internet of Things combined with Data Prediction in healthcare literature. This section also describes a taxonomy proposed in this work for IoT systems with Data Prediction applied to healthcare. Section 5 presents the possibilities and challenges for exploring the Internet of Things paradigm and Data Prediction techniques to improve healthcare processes and, finally, Section 6 presents the conclusions and proposed future works.

\section{BACKGROUND}

The use of Data Prediction combined with IoT applied to healthcare has several uses and a lot of potentials and can help to identify diseases and risk situations before they happen. After a literature review, only surveys that address the Internet of Things and healthcare in a common context were found. When the search was extended for Data Prediction, few surveys were found that bring some question related to forecast techniques. This is the case of the review conducted by Darshan and Anandakumar (2015) on the usage of IoT in the healthcare system and did not address the use of Data Prediction in any of the reviewed articles. The relation of the research with prediction is in the results since as the authors did not find an approach for prediction of chronic disorders in wearable devices context, they proposed a methodology for this. Another study is a survey conducted by Meharouech, Elias, and Mehaoua (2015) on ubiquitous healthcare. The focus of the research was on the use of ubiquitous devices for the health area, and some of the studies addressed, provided approaches for the mobility prediction of patients. Based on this, it can be noted that although there are surveys that address the use of IoT in the health area, there are still no surveys which combine Data Prediction in this area of study, that means there is no global view of it in the literature. Although there are taxonomies such as the one proposed by Meharouech et al. (2015), they focus only on IoT in the healthcare area and do not address Data Prediction.

\section{ARTICLE SELECTION}

This section presents a systematic review of the literature to identify and provide the state of the art of academic research in the healthcare area, related to the concept of Internet of Things, focusing on Data Prediction to predict and prevent problems. This type of literature review was selected to summarize the technology in relation to this topic, in a way that does not require in-depth analysis and synthesis. For this systematic literature review, the following activities were used, as reviewed by Roehrs et al. (2017):

1. Research Questions: Presents the research questions elaborated for this systematic review;

2. Search Strategy: Describes the explored libraries and the strategy to collect the data;

3. Article Selection: Define the steps taken to filter and select the studies;

4. Quality Assessment: Describe the quality assessment of the selected studies;

5. Data Extraction: Compare the selected papers and research questions.

\section{Research Questions}

According to Roehrs et al. (2017), the definition of research questions is one of the most important parts of any systematic literature review. This study aims to identify and classify the technology related to IoT use in healthcare combined with Data Prediction; the resources, problems, challenges, and solutions that are currently being considered; and the research opportunities that exist or are emerging. For this work, two types of questions were defined: General Question (QG) and Specific Questions (SQ). Table 1 shows the research questions raised for this search of works related to the research theme of this document. 
Table 1. Research questions

\begin{tabular}{|l|l|}
\hline \multicolumn{2}{|l|}{ Group and Identifier } \\
\hline General Question & How would the taxonomy for IoT systems with Data Prediction applied to healthcare appear? \\
\hline GQ1 & $\begin{array}{l}\text { What are the data that are included in an IoT system with Data Prediction applied to } \\
\text { healthcare? }\end{array}$ \\
\hline Specific Question & $\begin{array}{l}\text { What are the technologies and standards that apply to IoT systems with Data Prediction } \\
\text { applied to healthcare? }\end{array}$ \\
\hline SQ1 & $\begin{array}{l}\text { Which are the techniques or methods used to input information into IoT systems with Data } \\
\text { Prediction applied to healthcare? }\end{array}$ \\
\hline SQ2 & What are the goals of IoT systems with Data Prediction applied to healthcare? \\
\hline SQ3 & What are the architecture models of IoT systems with Data Prediction applied to healthcare? \\
\hline SQ4
\end{tabular}

The proposed General Question brings a broad classification related to the IoT systems with Data Prediction for the healthcare area. GQ1 refers to classifying and defining a taxonomy for existing IoT systems with Data Prediction applied to healthcare. To improve the filtering process of the studies, in order to guide and facilitate the process of identifying the answer for GQ1, some Specific Questions were defined. SQ1 seeks to identify the types of data an IoT system with Data Prediction applied to healthcare can contain. SQ2 investigates the types of standards that are used for IoT systems with Data Prediction applied to healthcare. SQ3 seeks to show how information is inserted into the proposed systems. SQ4 investigates what are the goals that IoT systems with Data Prediction applied to healthcare have. SQ5 focuses on architecture models for IoT systems with Data Prediction applied to healthcare.

\section{Search Strategy}

The next step was to identify a set of studies related to research questions. In this process, the search keywords and the definition of the search scope were defined. These words were defined to obtain research results focused on the theme of this systematic review. Therefore, the Search String located in Textbox 1 was defined for the search and selection of articles in electronic academic databases.

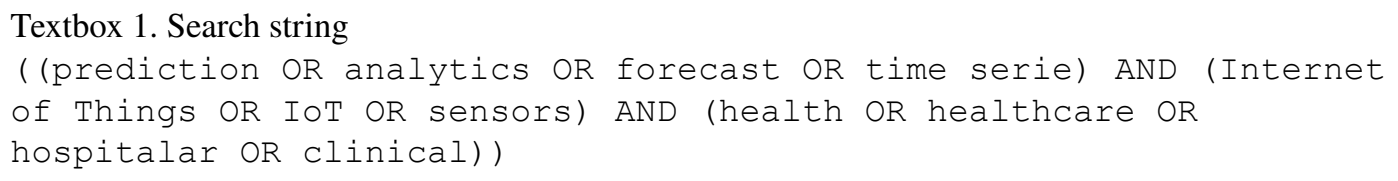

To cover a large number of related studies, several electronic scientific libraries were selected as the basis for research on the articles, listed in Table 2. According to Roehrs et al. (2017), these portals are some of that cover the most relevant journals and conferences of the computer science area. The period utilized for search in the electronic databases was between 2010 and 2018.

\section{Article Selection}

After all articles were found in the electronic databases using the Search String, were carried out a process of removing articles that would not be relevant to this research, in order to keep only those that would be more representative to the theme. Thus, all works that did not address the use of Internet of 
Table 2. Electronic databases for article search

\begin{tabular}{|l|l|}
\hline \multicolumn{1}{|c|}{ Acronym } & \multicolumn{1}{c|}{ Electronic Database Name } \\
\hline ACM & ACM Digital Library \\
\hline Google Scholar & Google Scholar \\
\hline IEEE & IEEE Xplore Digital Library \\
\hline IET & IET Digital Library \\
\hline PubMed & National Center for Biotechnology Information, U.S. National Library of Medicine \\
\hline ScienceDirect & Elsevier B. V. ScienceDirect \\
\hline Wiley & Wiley Online Library \\
\hline
\end{tabular}

Things combined with Data Prediction to prevent problems in healthcare were removed. Therefore, the following exclusion criterion was defined for article selection:

Exclusion Criterion 1: Article does not address the use of Internet of Things in healthcare.

Exclusion Criterion 2: Article does not address Data Prediction techniques to prevent problems.

According to Roehrs et al. (2017), an important step in the systematic review is the definition of the filtering process of the articles. As a result, the following steps were defined for the filtering and selection process: (I) Filter by Title, (II) Filter by Abstract, and (III) Filter by Full Text. First, the titles of the articles were analyzed, so that those who did not address the Internet of Things and Health were excluded, according to Exclusion Criterion 1. After, the abstract of the remaining articles was analyzed so that the articles that do not address the use of IoT in healthcare could be excluded, according to Exclusion Criterion 1. At the same stage, are also excluded the articles in which nothing was found in their abstracts regarding Data Prediction, according to Exclusion Criterion 2. Finally, the texts of the articles filtered in the previous stages were read and the exclusion criterion was applied again, removing those that did not address the proposal of that systematic review.

\section{Quality Assessment}

According to Roehrs et al. (2017), it is essential to evaluate the quality of the selected papers, in order to verify if it is really relevant to the study. Thus, the selected articles were evaluated in relation to the parameters used by Roehrs et al. (2017): the purpose of the research, contextualization, literature review, related works, methodology, results obtained and the conclusion, related to the proposed objectives, and an indication of future works. Based on this, Table 3 was elaborated, presenting the quality criteria in the form of questions to which the selected articles were submitted for validation of their quality.

\section{Data Extraction}

In order to gather the information about the paper previously raised, a comparison was made between the chosen articles and the research questions. Table 4 shows how they were compared, bringing each item of the related papers to the research, in order to have a better way to extract details of the articles and understand how studies have addressed issues related to the research questions proposed in the systematic literature review performed in this paper.

\section{Selected Studies}

In Table 5 all selected articles are presented, bringing: (I) An identifier for each of them, (II) Author names in bibliographic reference format, (III) The article Publisher, and (IV) Type of publication, 
Table 3. Quality assessment criteria

\begin{tabular}{|l|l|}
\hline \multicolumn{1}{|c|}{ Identifier } & \multicolumn{1}{c|}{ Criteria } \\
\hline C1 & Does the article clearly show the purpose of the research? \\
\hline C2 & Does the article adequately describe the research context through a literature review? \\
\hline C3 & Does the article present the related work to the main contribution? \\
\hline C4 & Does the article have a description of a proposed architecture or research methodology? \\
\hline C5 & Does the article present results for the research? \\
\hline C6 & Does the article present a study conclusion related to the research objectives? \\
\hline C7 & Does the article present some future work, improvements or some future study? \\
\hline
\end{tabular}

Table 4. Review of articles with research questions

\begin{tabular}{|l|l|l|}
\hline \multicolumn{1}{|c|}{ Section } & \multicolumn{1}{c|}{ Description } & Research Questions \\
\hline Metadata & Title of article & GQ1, SQ1, SQ2, SQ5 \\
\hline Title & Summary of paper with method and results & GQ1, SQ1, SQ2, SQ5 \\
\hline Abstract & Words representing the article content & GQ1, SQ1, SQ2, SQ5 \\
\hline Keywords & & All questions \\
\hline Article & Section introducing the addressed problem & All questions \\
\hline Introduction & Section presenting concepts about the article them & All questions \\
\hline Background & Presents the proposed scientific methodology & All questions \\
\hline Method & Covers results acquired after evaluation & SQ2-SQ5 \\
\hline Results & Compare article results with the literature & SQ2-SQ5 \\
\hline Discussion & Relate objectives and hypotheses & \\
\hline Conclusion & & \\
\hline
\end{tabular}

which may be Journal Article or Conference Article. The papers were sorted in ascending order by year of publication and, after, order by alphabetical order of authors' names.

\section{Performing the Quality Assessment}

In Figure 1 the satisfied Quality Criteria are presented for each of the selected works, based on the Quality Assessment Criteria proposed in Table 3. The criteria satisfied by each article are shown on the vertical axis, and the articles themselves on the horizontal axis, according to the Identifiers previously defined. After this quality assessment, it may be noted that most of the articles could reach 6 or 7 quality criteria.

\section{STATE OF THE ART}

Based on the selected articles, it was possible to identify that there are currently several fronts and approaches when the objective is to predict issues related to the health of a patient using the Internet of Things and Data Prediction concepts. Through the articles surveyed it was possible to see that it is not only possible to use the technology for this, as it is already being used in several approaches in the scientific community. Most of the IoT systems with Data Prediction applied to healthcare 
Table 5. Selected studies

\begin{tabular}{|c|c|c|c|}
\hline Identifier & Authors (Year) & Publisher & Type \\
\hline A01 & Kwon, Shin, Shin, and Kim (2010) & IEEE & Conference \\
\hline A02 & Kan, Chen, Leonelli, and Yang (2015) & IEEE & Conference \\
\hline A03 & Kang, Adibi, Larkin, and Luan (2015) & IEEE & Conference \\
\hline A04 & Orimaye, Leong, Lee, and $\mathrm{Ng}$ (2015) & IEEE & Conference \\
\hline A05 & Jouini, Lemlouma, Maalaoui, and Saidane (2016) & IEEE & Conference \\
\hline A06 & Azimi et al. (2017) & $\mathrm{ACM}$ & Journal \\
\hline A07 & Chen, Chen, Wu, Hu, and Pan (2017) & Elsevier & Journal \\
\hline A08 & Robben, Englebienne, and Kröse (2017) & IEEE & Journal \\
\hline A09 & Zamanifar, Nazemi, and Vahidi-Asl (2017) & Elsevier & Journal \\
\hline A10 & Ali et al. (2018) & Elsevier & Journal \\
\hline A11 & Basanta, Huang, and Lee (2018) & IEEE & Conference \\
\hline A12 & Bhatia and Sood (2018a) & Elsevier & Journal \\
\hline A13 & Bhatia and Sood (2018b) & Springer & Journal \\
\hline A14 & Farahani et al. (2018) & Elsevier & Journal \\
\hline A15 & Gondalia et al. (2018) & Elsevier & Journal \\
\hline A16 & Huang, Zhao, Zhou, and Jiang (2018) & IEEE & Journal \\
\hline A17 & Kumar, Lokesh, Varatharajan, Babu, and Parthasarathy (2018) & Elsevier & Journal \\
\hline A18 & Manogaran et al. (2018) & Elsevier & Journal \\
\hline A19 & Paudel, Dunn, Eberle, and Chaung (2018) & AAAI & Conference \\
\hline A 20 & Sood and Mahajan (2018) & IEEE & Journal \\
\hline A 21 & Tan and Halim (2018) & Taylor \& Francis & Journal \\
\hline A 22 & Thakur et al. (2018) & MDPI & Journal \\
\hline A 23 & Verma, Sood and Kalra (2018) & Springer & Journal \\
\hline
\end{tabular}

Figure 1. Satisfied quality criteria for each selected article

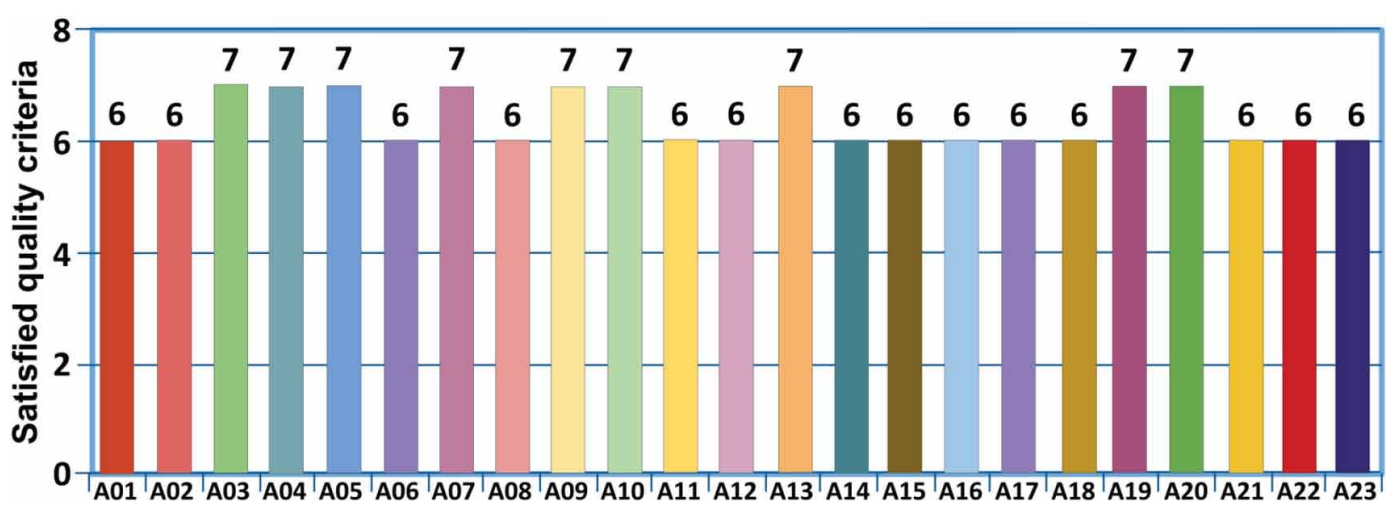


researched focus on the monitoring of the patient's health conditions, in order to generate alerts if any risk situations are identified. These systems are able to predict when the patient's vital signs will be at risk, identify health problems and diseases, and environmental risk situations for patients. Table 6 presents a comparison between the collected papers, relating some of their main characteristics.

Based on the Research Questions defined in Research Questions Section, was performed the data extraction process of the selected articles in order to determine the State of the Art of Internet of Things and Data Prediction in healthcare systems. Next, are presented the General Question and the Specific Questions used to help answer the General Question, along with the answers found for each of them.

\section{GQ1: How Would the Taxonomy for loT Systems With Data Prediction Applied to Healthcare Appear?}

Were investigated several studies that work with the concept of Internet of Things and Data Prediction applied to situations in the healthcare area. When analyzing the selected articles, it was possible to propose a taxonomy based on important characteristics of the models, in order to help in the classification, comparison, and evaluation of different IoT systems for health. In addition, this classification can provide an overview of possible alternatives in terms of objectives, content, and architectures. The proposed taxonomy is summarized in Table 7, divided into three groups: (I) Structures, (II) Functions and (III) Architecture. Next to each item have a brief description.

Figure 2 presents the proposed taxonomy, bringing the entire classification for IoT systems with Data Prediction applied to healthcare. The next sections of this article present the subclassifications proposed in Table 7, showing how this taxonomy was proposed, also presenting which studies have used each of the structures, functions, and architectures proposed in this work.

\section{SQ1: What are the Data That are Included in an IoT System With Data Prediction Applied to Healthcare?}

To answer this question were analyzed all previously selected articles. The types of data that are included in IoT systems with Data Prediction applied to healthcare are described in Table 8. The data types found are as follows: (I) Activities that a particular patient may be performing, (II) Status of the environment where the patient is located, (III) Data sources, internal or external, with information on diseases, treatments, diagnoses and others, (IV) Data captured through Social Networks, (V) Location of the patient in an environment in any instant of time, (VI) Patient's vital signs captured by the system in real time and (VII) Patient's vital signs captured by examinations and measurements, subsequently inputted into the system. Table 8 lists all data types found and a brief description of each of them.

\section{SQ2: What are the Technologies and Standards That Apply to IoT Systems With Data Prediction Applied to Healthcare?}

Many studies use own formats to organize the data they use so that there is not always a standard among them. Thus, there are many technologies that can be used for IoT systems with Data Prediction applied to healthcare. However, in order to answer this question, were analyzed the open industry standards and other technologies that are used in these articles. As there are numerous technologies in this aspect, it was decided to list only those used by more than one article studied. Table 9 presents them, some of them being: Bluetooth, Cloud and Fog Computing, Global Positioning System (GPS), Radio Frequency Identification (RFID), Wireless Body Area Network (WBAN), Wearables, Wireless Sensor Network (WSN), and ZigBee.

\section{SQ3: Which are the Techniques or Methods Used to Input Information Into loT Systems With Data Prediction Applied to Healthcare?}

Another result of this systematic literature review was the identification of the techniques used by the IoT systems with Data Prediction applied to healthcare to perform the insertion of data and 
Table 6. Comparative between characteristics of the articles

\begin{tabular}{|c|c|c|c|c|c|c|c|c|c|c|c|c|c|c|c|c|c|c|c|c|c|c|c|}
\hline \multirow[b]{2}{*}{ Characteristics } & \multicolumn{23}{|c|}{ Reference Articles } \\
\hline & $\overline{\mathrm{e}}$ & $\overparen{ֶ}$ & 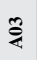 & $\stackrel{\Xi}{4}$ & $\stackrel{20}{4}$ & 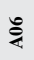 & $\stackrel{\xi}{4}$ & $\stackrel{\infty}{\sharp}$ & غे & $\stackrel{\varrho}{\gtrless}$ & $\bar{z}$ & $\stackrel{2}{4}$ & $\frac{3}{4}$ & $\underset{⿱}{Z}$ & $\frac{20}{4}$ & $\frac{e}{4}$ & 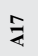 & $\stackrel{\infty}{\gtrless}$ & $\frac{\vartheta}{\gtrless}$ & ๙ิ & হৃ & สี & đ্ \\
\hline \multicolumn{24}{|c|}{ Presents mechanisms for security such as } \\
\hline $\begin{array}{l}\text { Authentication and Authorization } \\
\text { of users }\end{array}$ & & & & & & $\bullet$ & & & & $\bullet$ & $\bullet$ & • & $\bullet$ & • & & & • & & & & & & • \\
\hline Data encryption & & & & & & - & & & & & - & & $\bullet$ & $\bullet$ & & & $\bullet$ & - & & & & & $\bullet$ \\
\hline \multicolumn{24}{|l|}{ Patient privacy } \\
\hline \multicolumn{24}{|l|}{ Uses the following techniques } \\
\hline Cloud Computing & & - & - & & & - & & & & & - & • & $\bullet$ & - & - & - & $\bullet$ & $\bullet$ & & - & - & & $\bullet$ \\
\hline Fog Computing & & & & & & $\bullet$ & & & & & & & • & $\bullet$ & & & & $\bullet$ & & $\bullet$ & & & \\
\hline Data Prediction & $\bullet$ & - & • & $\bullet$ & $\bullet$ & - & $\bullet$ & • & $\bullet$ & $\bullet$ & $\bullet$ & $\bullet$ & $\bullet$ & $\bullet$ & $\bullet$ & - & • & $\bullet$ & $\bullet$ & - & - & $\bullet$ & $\bullet$ \\
\hline \multicolumn{24}{|c|}{ Uses the following techniques to perform prediction } \\
\hline Artificial Intelligence & & & & • & & - & • & & & $\bullet$ & & • & - & & - & & • & & • & - & - & • & - \\
\hline Big Data & & & & & & & & & & & & & & - & & & & $\bullet$ & & & & & \\
\hline Probability and statistics & - & • & • & & $\bullet$ & & & $\bullet$ & $\bullet$ & & $\bullet$ & & & & & - & & $\bullet$ & $\bullet$ & & & $\bullet$ & \\
\hline \multicolumn{24}{|c|}{ Use the following prediction algorithms and models } \\
\hline Adaptative Boosting (AdaBoost) & & & & & & & & & & & & & & & & & & & $\bullet$ & & & $\bullet$ & \\
\hline $\begin{array}{l}\text { Artificial Neural Networks } \\
\text { (ANN) }\end{array}$ & & & & & & & $\bullet$ & & & & & $\bullet$ & & & & & & & & • & • & & \\
\hline \multicolumn{24}{|l|}{ Decision Tree } \\
\hline Fuzzy Logic & & & & & & & & & & $\bullet$ & & & & & & & $\bullet$ & & & & & & \\
\hline \multicolumn{24}{|l|}{ K-Means clustering } \\
\hline K-Nearest Neighbors & & & & & & & & & & & & & & & & & & & $\bullet$ & & & $\bullet$ & $\bullet$ \\
\hline \multicolumn{24}{|l|}{ Linear Discriminant Analysis } \\
\hline Random Forest & & & & & & & & & & & & & & & & & & & $\bullet$ & & & - & \\
\hline Support Vector Machines (SVM) & & & & $\bullet$ & & - & & & & & & & & & & & & & $\bullet$ & & & $\bullet$ & \\
\hline \multicolumn{24}{|l|}{ Temporal Naive Bayes (TNB) } \\
\hline \multicolumn{24}{|l|}{$\begin{array}{l}\text { Disease Combination Appearance } \\
\text { Probability (DCAP) }\end{array}$} \\
\hline Bayesian inference & & & $\bullet$ & & & & & & & & & & & & & - & & & & & & & \\
\hline \multicolumn{24}{|l|}{ Gaussian function } \\
\hline \multicolumn{24}{|l|}{ Grey Model } \\
\hline \multicolumn{24}{|l|}{ Hidden Markov } \\
\hline \multicolumn{24}{|l|}{ Linear Regression } \\
\hline Logistic Regression & & & & & & & & & & & & & & & & & & - & - & & & - & \\
\hline \multicolumn{24}{|l|}{$\begin{array}{l}\text { Multi Criteria Decision Making } \\
\text { Analytical Hierarchy Process } \\
\text { (MCDM-AHP) }\end{array}$} \\
\hline \multicolumn{24}{|l|}{ Regression Forest., } \\
\hline Performs prediction for the follo & ng c & & & & & & & & & & & & & & & & & & & & & & \\
\hline $\begin{array}{l}\text { Future status of vital signs and } \\
\text { conditions of the patient's health }\end{array}$ & $\bullet$ & & • & & $\bullet$ & $\bullet$ & & • & & $\bullet$ & & $\bullet$ & & $\bullet$ & $\bullet$ & & & & & $\bullet$ & & • & $\bullet$ \\
\hline Anticipate risk situations for patients & & & & & & & • & & & & & & & & & - & & & & & & & \\
\hline $\begin{array}{l}\text { Identify the patient's future } \\
\text { location }\end{array}$ & & & & • & & & & & $\bullet$ & & & & & & & & & & & & & & \\
\hline $\begin{array}{l}\text { Identify the incidence of diseases } \\
\text { in future }\end{array}$ & & $\bullet$ & & & & & & & & & - & & & & & & • & $\bullet$ & & - & • & & $\bullet$ \\
\hline
\end{tabular}


Table 7. IoT systems with data prediction applied to healthcare taxonomy summarized

\begin{tabular}{|l|l|}
\hline \multicolumn{1}{|c|}{ Group } & \multicolumn{1}{c|}{ Description } \\
\hline Structures & Data and technologies used in IoT systems with Data Prediction \\
\hline Data & Data found in the systems (See Table 8) \\
\hline Technologies & Technologies that can be applied in the systems (See Table 9) \\
\hline Functions & Describes the main objectives and characteristics present in the systems \\
\hline Data Source & Techniques for input information in the systems (See Table 10) \\
\hline Objectives & Represents the aim of the systems (See Table 11) \\
\hline Architecture & Architecture types (See Table 12) \\
\hline Models & Describes the architecture models \\
\hline Prediction & Presents which prediction models were used \\
\hline
\end{tabular}

Figure 2. IoT systems with data prediction applied to healthcare taxonomy

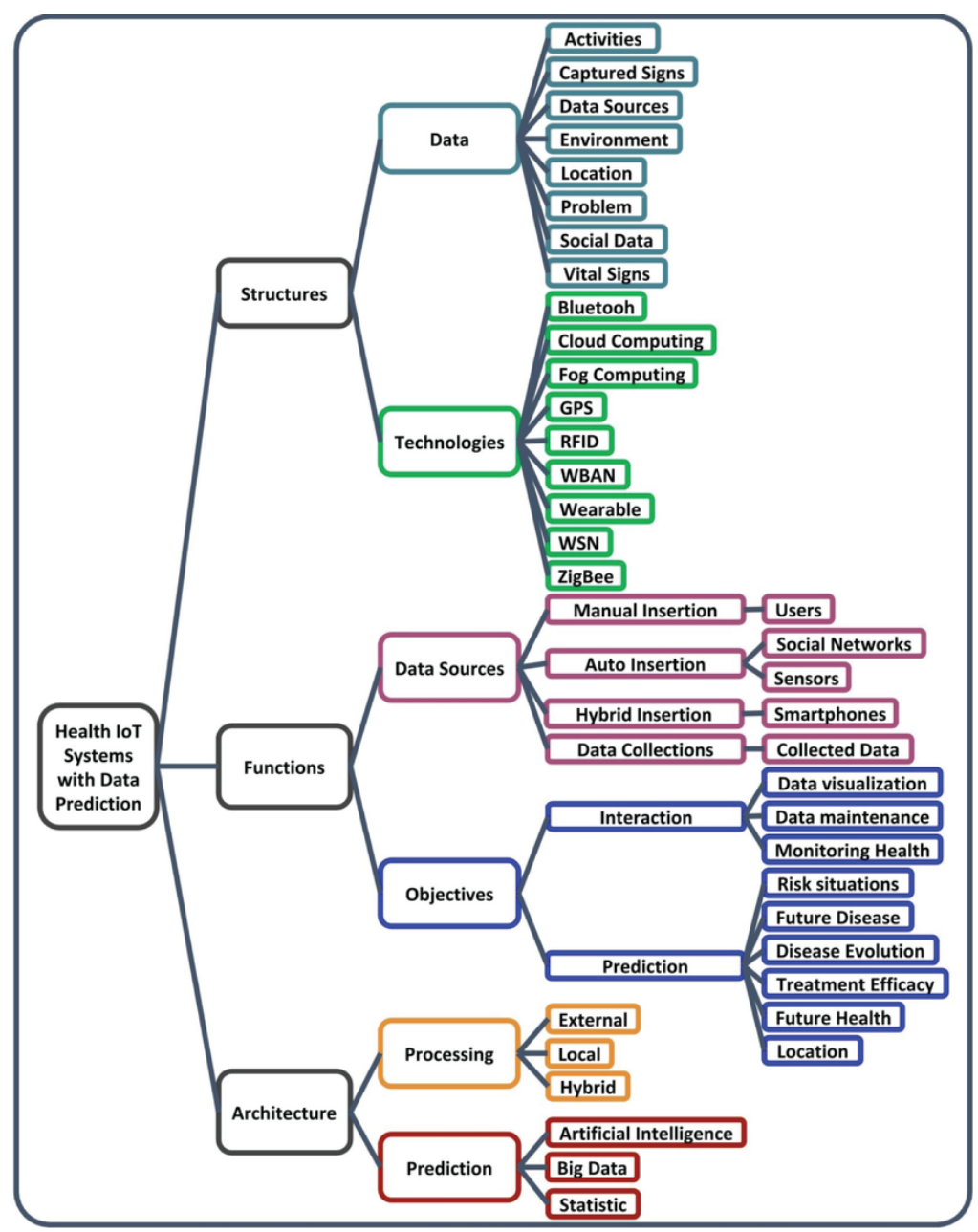


Table 8. Data found in loT systems with data prediction applied to healthcare

\begin{tabular}{|c|c|c|c|c|c|c|c|c|c|c|c|c|c|c|c|c|c|c|c|c|c|c|c|c|}
\hline \multirow[b]{2}{*}{ Data } & \multirow[b]{2}{*}{ Description } & \multicolumn{23}{|c|}{ Reference Articles } \\
\hline & & $\bar{\varepsilon}$ & 气̂́ & $\stackrel{0}{4}$ & $\stackrel{5}{\natural}$ & $\frac{10}{4}$ & $\stackrel{2}{4}$ & $\stackrel{5}{\&}$ & $\stackrel{\infty}{q}$ & $\hat{g}$ & $\stackrel{\varrho}{z}$ & $\bar{z}$ & $\frac{2}{4}$ & $\frac{3}{4}$ & $\frac{\pi}{4}$ & $\frac{10}{4}$ & $\stackrel{2}{4}$ & $\frac{5}{4}$ & $\stackrel{\infty}{<}$ & $\frac{\vartheta}{z}$ & ฉิ & $\bar{ষ}$ & สุ & $\frac{\pi}{4}$ \\
\hline Activities & $\begin{array}{l}\text { Activities that } \\
\text { the patient is } \\
\text { performing }\end{array}$ & & & $\bullet$ & & & $\bullet$ & & $\bullet$ & & & $\bullet$ & $\bullet$ & $\bullet$ & & $\bullet$ & & & & $\bullet$ & & & & \\
\hline $\begin{array}{l}\text { Captured } \\
\text { signs }\end{array}$ & $\begin{array}{l}\text { Vital signs not } \\
\text { captured by the } \\
\text { system }\end{array}$ & & & & & • & & & • & & & & & $\bullet$ & & & & & $\bullet$ & & $\bullet$ & & $\bullet$ & $\bullet$ \\
\hline Data sources & $\begin{array}{l}\text { Data sources with } \\
\text { information on } \\
\text { diseases, treatments } \\
\text { and related }\end{array}$ & & $\bullet$ & & & & • & $\bullet$ & & & $\bullet$ & $\bullet$ & $\bullet$ & & & & & $\bullet$ & $\bullet$ & & & $\bullet$ & & $\bullet$ \\
\hline Environment & $\begin{array}{l}\text { Status of } \\
\text { the patient's } \\
\text { environment }\end{array}$ & & & $\bullet$ & & & & $\bullet$ & & & & $\bullet$ & $\bullet$ & $\bullet$ & & $\bullet$ & $\bullet$ & & & $\bullet$ & $\bullet$ & & & $\bullet$ \\
\hline Location & $\begin{array}{l}\text { Where the patient is } \\
\text { in an environment }\end{array}$ & & & • & • & & • & $\bullet$ & • & • & & & & & & • & & & & $\bullet$ & $\bullet$ & & & \\
\hline Problem & $\begin{array}{l}\text { Identified health } \\
\text { problem }\end{array}$ & $\bullet$ & $\bullet$ & $\bullet$ & & • & $\bullet$ & & $\bullet$ & & $\bullet$ & $\bullet$ & & & & & & & $\bullet$ & $\bullet$ & $\bullet$ & $\bullet$ & & $\bullet$ \\
\hline Social Data & Social media data & & & & & & & $\bullet$ & & & & & & & & & & & & & & & & \\
\hline Vital signs & $\begin{array}{l}\text { Body function } \\
\text { Status }\end{array}$ & • & $\bullet$ & $\bullet$ & & & • & & & & • & $\bullet$ & • & $\bullet$ & $\bullet$ & $\bullet$ & $\bullet$ & & $\bullet$ & & • & $\bullet$ & $\bullet$ & $\bullet$ \\
\hline
\end{tabular}

Table 9. IoT systems with data prediction applied to healthcare related technologies

\begin{tabular}{|c|c|c|c|c|c|c|c|c|c|c|c|c|c|c|c|c|c|c|c|c|c|c|c|c|}
\hline \multirow[b]{2}{*}{ Technology } & \multirow[b]{2}{*}{ Description } & \multicolumn{23}{|c|}{ Reference Articles } \\
\hline & & $\overline{\mathrm{z}}$ & $\stackrel{\tilde{z}}{4}$ & $\stackrel{\%}{4}$ & $\frac{\pi}{4}$ & $\stackrel{20}{4}$ & 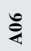 & $\hat{q}$ & $\stackrel{\infty}{2}$ & ङे & 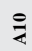 & $\bar{z}$ & $\cong$ & $\frac{m}{4}$ & $\frac{\pi}{4}$ & $\frac{n}{4}$ & $\dddot{2}$ & $\xi$ & $\stackrel{\infty}{4}$ & $\frac{\vartheta}{4}$ & ণิ & $\overline{\mathcal{Z}}$ & $\underset{殳}{\gtrless}$ & ชู \\
\hline Bluetooth & $\begin{array}{l}\text { Wireless technology } \\
\text { standard }\end{array}$ & - & - & & & & & & & & & & - & & - & & & & & & & & & \\
\hline $\begin{array}{l}\text { Cloud } \\
\text { Computing }\end{array}$ & $\begin{array}{l}\text { Technology for } \\
\text { delivery of on- } \\
\text { demand computing } \\
\text { resources over the } \\
\text { internet }\end{array}$ & & - & - & & & - & & & & & - & - & - & - & - & & & - & & - & - & & \\
\hline $\begin{array}{l}\text { Fog } \\
\text { Computing }\end{array}$ & $\begin{array}{l}\text { Cloud } \\
\text { geographically } \\
\text { close to the user for } \\
\text { latency-sensitive } \\
\text { applications }\end{array}$ & & & & & & - & & & & & & & - & - & & & & - & & - & & & \\
\hline GPS & $\begin{array}{l}\text { satellite-based radio } \\
\text { navigation system }\end{array}$ & & & & & & & & & & & & & & & - & & & & & - & & & \\
\hline RFID & $\begin{array}{l}\text { Standard for } \\
\text { identification }\end{array}$ & & & - & & & & & & & - & & - & - & • & & & & & & - & & & \\
\hline WBAN & Sensor network & & & - & - & & & & & - & - & & & & & & & & & & & & & \\
\hline Wearable & Wearable & & & & & & & & & & & - & - & - & - & - & & - & - & & & & & - \\
\hline WSN & Sensor network & & & & & & & & & - & & & & & - & & & & & & & & & \\
\hline ZigBee & $\begin{array}{l}\text { Suite of high level } \\
\text { communica-tion } \\
\text { protocols }\end{array}$ & - & & & & & & & & & & & & & - & - & - & & & & & & & \\
\hline
\end{tabular}

information into the applications. Table 10 presents the techniques for insertion of the data in the systems proposed in these articles, bringing a description of each of these techniques. The techniques are divided into four main groups: Data Collection (T1), where the data is inserted through previously created collections of data; Auto Insertion (T2), where information is captured automatically through some techniques and entered into the application; Manual Insertion (T3), where information must 
Table 10.

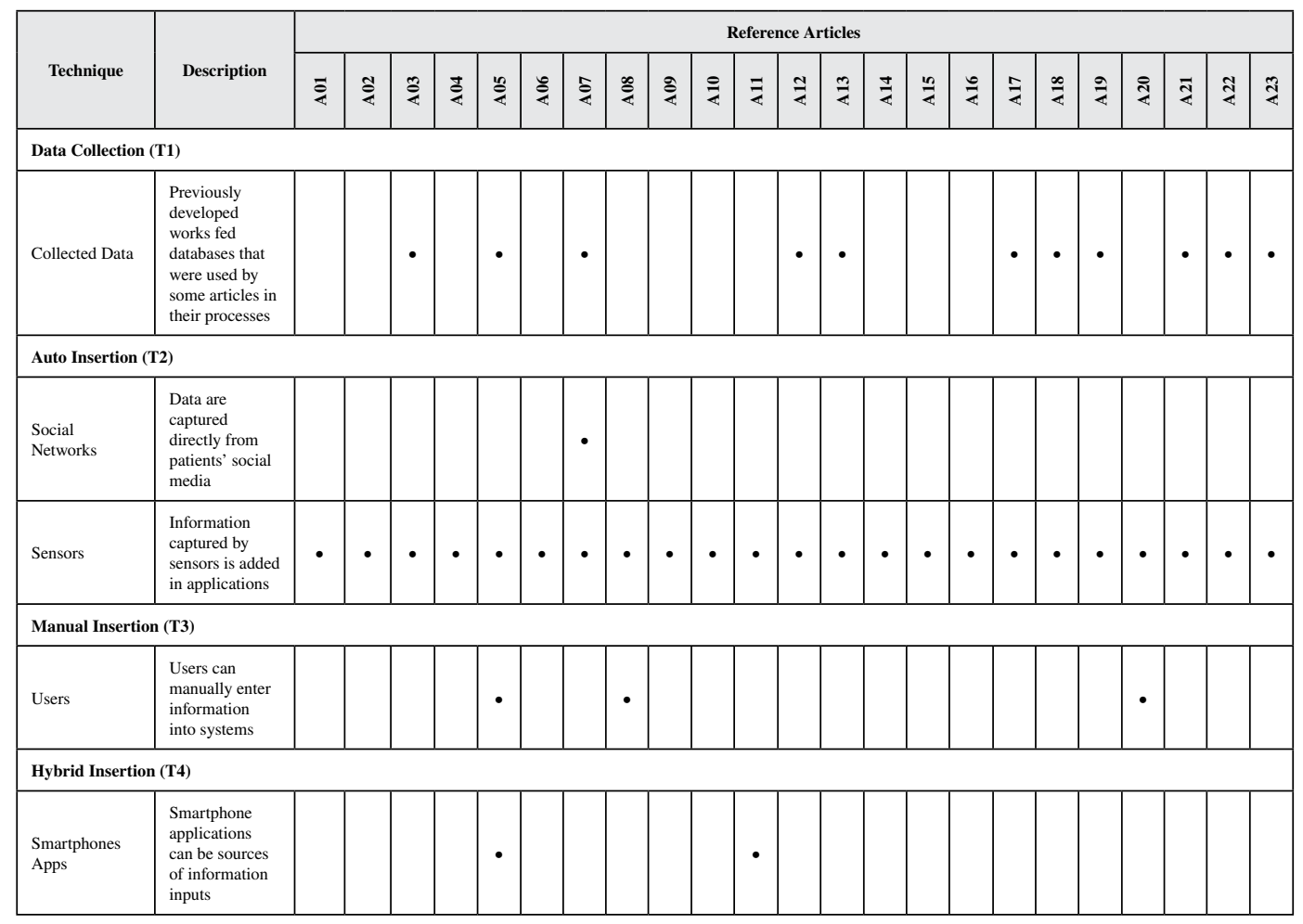

be entered manually into the application; Hybrid Insertion (T4), where the same technique can enter information in the system either manually or automatically.

\section{SQ4: What are the Goals of IoT Systems With Data Prediction Applied to Healthcare?}

This research question presents the main goals or objectives of IoT systems with Data Prediction applied to healthcare. Table 11 presents the objectives found for the articles analyzed in this systematic literature review. It was concluded that the objectives can be divided into two categories: Interaction (O1), that are related to the way of the system will interact with the patients and other users, and Prediction (O2), which are related to the predictions that the system intends to perform in order to prevent in advance life-threatening situations which patients may be exposed.

\section{SQ5: What are the Models of Architecture of IoT Systems With Data Prediction Applied to Healthcare?}

This last specific question aims to identify the main models of architectures used by IoT systems with Data Prediction applied to healthcare in their implementations. After analyzing the articles, were defined two main architecture groups (as shown in Table 12): Processing (A1), which presents the data processing architectures, which are classified in Local, External or Hybrid, and Prediction (A2), which presents the techniques used for the Data Prediction architecture, such Artificial Intelligence, Big Data, and Probability and statistics. 
Table 11. Objectives related to the form of interaction with the system and to the predictions that the system intends to perform

\begin{tabular}{|c|c|c|c|c|c|c|c|c|c|c|c|c|c|c|c|c|c|c|c|c|c|c|c|}
\hline \multirow[b]{2}{*}{ Objectives } & \multicolumn{23}{|c|}{ Reference Articles } \\
\hline & $\overline{\mathrm{e}}$ & 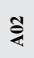 & $\stackrel{\overbrace{}}{\psi}$ & ఫ্ & $\stackrel{\leftrightarrow}{2}$ & 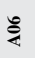 & $\stackrel{5}{4}$ & $\stackrel{\infty}{\&}$ & $\stackrel{\bigotimes}{\&}$ & $\stackrel{\varrho}{4}$ & $\Xi$ & $\stackrel{2}{4}$ & $\frac{9}{2}$ & $\frac{\pi}{2}$ & $\frac{12}{4}$ & $\frac{0}{4}$ & 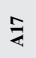 & $\stackrel{\infty}{\gtrless}$ & $\stackrel{\gtrless}{\gtrless}$ & ָิ & ্ָ & ส̃ & $\underset{4}{2}$ \\
\hline \multicolumn{24}{|l|}{ Interaction (O1) } \\
\hline $\begin{array}{l}\text { Objective patient data } \\
\text { visualization in a query } \\
\text { tool }\end{array}$ & $\bullet$ & & - & & & & & & & & & & & • & $\bullet$ & $\bullet$ & $\bullet$ & & $\bullet$ & & $\bullet$ & & \\
\hline \multicolumn{24}{|l|}{$\begin{array}{l}\text { Objective the maintenance } \\
\text { of patient data for } \\
\text { themselves or/and for } \\
\text { other users of the system, } \\
\text { manually }\end{array}$} \\
\hline $\begin{array}{l}\text { Objective monitoring of } \\
\text { the health conditions of } \\
\text { the patient, in order to } \\
\text { generate alerts when a } \\
\text { problem identified }\end{array}$ & $\bullet$ & - & $\bullet$ & $\bullet$ & $\bullet$ & $\bullet$ & $\bullet$ & $\bullet$ & $\bullet$ & $\bullet$ & $\bullet$ & $\bullet$ & $\bullet$ & $\bullet$ & & & & $\bullet$ & & & & $\bullet$ & $\bullet$ \\
\hline \multicolumn{24}{|l|}{ Prediction $(\mathrm{O} 2)$} \\
\hline $\begin{array}{l}\text { Predict risk situations that } \\
\text { patients may be exposed }\end{array}$ & & & & & & & $\bullet$ & & & & & & & & & $\bullet$ & & & & $\bullet$ & & & \\
\hline Predict heart disease & & $\bullet$ & & & & $\bullet$ & & & & & $\bullet$ & & & & & & $\bullet$ & $\bullet$ & $\bullet$ & $\bullet$ & $\bullet$ & & $\bullet$ \\
\hline $\begin{array}{l}\text { Predict future conditions } \\
\text { or vital signs of patients' } \\
\text { health }\end{array}$ & $\bullet$ & & $\bullet$ & & $\bullet$ & $\bullet$ & & $\bullet$ & & $\bullet$ & & $\bullet$ & - & • & $\bullet$ & & & & & $\bullet$ & & $\bullet$ & $\bullet$ \\
\hline $\begin{array}{l}\text { Predict where the patient } \\
\text { will be next, in order } \\
\text { to prepare the sensors } \\
\text { installed in the healthcare } \\
\text { environment to collect the } \\
\text { patient information in a } \\
\text { non-invasive way }\end{array}$ & & & & $\bullet$ & & & & & $\bullet$ & & & & & & & & & & & & & & \\
\hline
\end{tabular}

\section{Table 12. Models of data processing and prediction}

\begin{tabular}{|c|c|c|c|c|c|c|c|c|c|c|c|c|c|c|c|c|c|c|c|c|c|c|c|c|}
\hline \multirow[b]{2}{*}{ Model } & \multirow[b]{2}{*}{ Description } & \multicolumn{23}{|c|}{ Reference Articles } \\
\hline & & $\overline{\mathrm{s}}$ & $\stackrel{\varrho}{q}$ & $\stackrel{\overbrace{}}{\varepsilon}$ & $\frac{\Xi}{2}$ & $\stackrel{4}{4}$ & 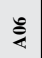 & $\hat{\varepsilon}$ & $\stackrel{\circ}{\varrho}$ & 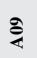 & $\stackrel{e}{2}$ & $\bar{z}$ & $\stackrel{2}{2}$ & $\frac{3}{4}$ & $\frac{J}{4}$ & $\frac{n}{2}$ & $\stackrel{2}{\gtrless}$ & $\stackrel{5}{4}$ & $\stackrel{\infty}{\gtrless}$ & $\frac{2}{4}$ & ఇิ & হৃ & $\underset{殳}{*}$ & $\frac{3}{4}$ \\
\hline \multicolumn{25}{|c|}{ Processing (A1) } \\
\hline Local & $\begin{array}{l}\text { Data is processed } \\
\text { locally }\end{array}$ & & & & $\bullet$ & • & & & & • & & & & & & & & & & • & & & • & \\
\hline External & $\begin{array}{l}\text { Processing } \\
\text { occurs on } \\
\text { external server }\end{array}$ & & $\bullet$ & & & & & $\bullet$ & $\bullet$ & & $\bullet$ & $\bullet$ & & & & $\bullet$ & & $\bullet$ & & & & & & \\
\hline Hybrid & $\begin{array}{l}\text { Data is processed } \\
\text { in parts locally } \\
\text { and in parts on an } \\
\text { external server }\end{array}$ & $\bullet$ & & $\bullet$ & & & $\bullet$ & & & & & & $\bullet$ & $\bullet$ & $\bullet$ & & $\bullet$ & & $\bullet$ & & $\bullet$ & $\bullet$ & & - \\
\hline \multicolumn{25}{|c|}{ Prediction (A2) } \\
\hline $\begin{array}{l}\text { Artificial } \\
\text { Intelligence }\end{array}$ & $\begin{array}{l}\text { Performed } \\
\text { through Artificial } \\
\text { Intelligence } \\
\text { techniques }\end{array}$ & & & & & & & $\bullet$ & & & $\bullet$ & & $\bullet$ & & & $\bullet$ & & $\bullet$ & & $\bullet$ & $\bullet$ & $\bullet$ & $\bullet$ & $\bullet$ \\
\hline Big Data & $\begin{array}{l}\text { Performed } \\
\text { through Big Data } \\
\text { techniques }\end{array}$ & & & & & & & & & & & & & & $\bullet$ & & $\bullet$ & & $\bullet$ & & & & & \\
\hline $\begin{array}{l}\text { Probability } \\
\text { and Statistics }\end{array}$ & $\begin{array}{l}\text { Performed using } \\
\text { probability } \\
\text { and statistics } \\
\text { techniques }\end{array}$ & $\bullet$ & $\bullet$ & $\bullet$ & $\bullet$ & - & $\bullet$ & & $\bullet$ & $\bullet$ & & $\bullet$ & & $\bullet$ & & & $\bullet$ & & $\bullet$ & $\bullet$ & & & $\bullet$ & \\
\hline
\end{tabular}




\section{CHALLENGES AND POSSIBILITIES}

It was possible to observe that there are currently several fronts and approaches when the goal is to take care of the health of patients using the Internet of Things concept, and not only this but to anticipate problem situations through Data Prediction techniques. Several systems use different techniques to achieve the same goals. When looking at these systems, it is possible to note that concepts such as Cloud Computing, Fog Computing, Artificial Intelligence, Big Data, Probability, and Statistics are at the top of the world's health research. However, few of these approaches have effective mechanisms to deal with the issue of security in the digital age. And those who have them do not always rely on extremely secure protocols and systems. Some applications do not make use of adaptive computing resources like Cloud Computing, using own resources and own servers that end up becoming single points of failure and, because of that dependability, if a single service stops working, the entire application will fail.

Furthermore, there are many techniques for analyzing the future status of the patient's health conditions, but practically none to predict the evolution of the diseases that the patient already has. The approaches are very focused on analyzing patient health conditions and focus very little on risk situations in the environment where the patient is inserted. Even in this regard, neither approach attempts to analyze the use of hospital resources and, consequently, to predict when these resources will become insufficient for patients care. Thus, it is possible to say that the technology needed to better explore the Internet of Things concept and Data Prediction in healthcare environments exists and is already used today, but there are few approaches that can merge concepts into one to solve several of the problems raised.

\section{Distributed Environments and Dependability}

As can be seen, only half of the approaches studied make use of Cloud Computing and the other half operate on own, apparently centralized, servers. One of the main problems of working with a centralized environment is dependability, that is, with the system running on a single server, if it fails, the entire application will fail. Often, there are several services and servers to perform all the tasks, which makes the problem even worse, because if any one of them fails, the whole application stops working, and will have several services and servers running, but nothing to process.

In this context, a possibility of exploration would be to create techniques and systems capable of operating over distributed environments, with data replication and redundancy of services and servers. One way to do this would be by using the Cloud Computing concept, maintaining the Health IoT application with Data Prediction in a cloud instance. However, one of the major problems of IoT is a large amount of data generated by the most diverse sensors. This way, transmitting all the data to the cloud can take considerable time, and until the data is processed by the application, the problem that is waiting to be predicted will already have happened. Thus, another possibility of exploration would be to propose systems that use Fog Computing, that is, clouds closer to the user, making the transmission occur faster and, in this context, to create techniques to pre-process the data in an appropriate way, eliminating noise and sending only what is needed for the main cloud to perform data processing.

Also, in this context of distributed applications, another possibility of exploration would be to define techniques for virtualization of services, that is, to define techniques to instantiate virtual machines to meet the processing demand, and to perform load balancing between them. Thus, the system would become able to increase and decrease the capacity as required. In this possibility, ways could be proposed to identify when a system is close to reaching its processing limit, to trigger a new virtual machine and, at the same time, to identify the underutilization of the system to disable virtual machines. Also, in this context, techniques could be proposed to divide the tasks between the machines appropriately. 


\section{Internet of Things Standards and Technologies}

One of the major problems and challenges for the Internet of Things is the absence of standards for data. The proposed systems have different ways of storing data, performing processing, and making it available to users. Data captured by one application can hardly be used by another. The few data that can be used, need an intermediate processing, only to carry out the translation of the same between the applications. Some approaches used the CoAP for data transfer. Others have used ontologies to store the knowledge acquired by the application and others have made web-services. Regarding the network, has the use of LoWPAN, WSN, and WBAN. One of the most used standards was the WBAN, presented in five of the articles. The few standards presented in the articles are not being used even for half of the studies studied. One of the premises of the Internet of Things is precisely the fact that all things and sensors capture full-time data to be used by the most diverse applications, but if there is no portability between them, would have only sensor systems and not a true Internet of Things.

In this context, a great possibility of exploration and studies would be to propose standards for the Internet of Things in health's area. Thus, standard architectures for systems could be proposed, for all research to follow the same path that works. Another idea would be to propose standards for the data captured by the sensors, so any data captured by any sensor of any application could be used by any other application. Even in this context, another possibility could be the proposal for data standards handled by these applications. In this way, the output data of an approach could be used as input to any other approach. Thus, the systems proposed by several future studies would have the capacity to exchange information between them in a natural and intuitive way, to effectively realize a collaborative Internet of Things, utilizing the full potential of technology.

\section{SECURITY AND PRIVACY}

Another point to be highlighted after analyzing the articles is the issue of security and privacy. Few approaches have been concerned with the safety of patient data. And even fewer have been able to implement adequate systems to address this problem. The security and privacy problem is extremely critical to the Internet of Things. With data being generated about users, and the objects that belong to them, the amount of information that can be generated is incalculable. In addition, in most cases, this information can be classified as confidential, since users would not like to make it available to third parties. Thus, the need to provide resources to deal with the security and privacy of data captured is extremely valuable to the scientific and industrial approaches.

In this context, a possibility of exploration would be systems capable of implementing an efficient and transparent layer of security to the users, that can protect the data of the same of a simple, but safe, way. Currently, one of the technologies that have been gaining a lot of prominences when it comes to data security is Blockchain. Blockchain provides an interesting approach to maintaining reliable databases on untrusted networks. Initially, it was used in Bitcoin proposed by Nakamoto (2008) as a data structure, becoming a technological solution that provides security in distributed systems (Jin, Zang, Liu, \& Lei, 2017). According to Kuzuno and Karam (2017), Blockchain is an electronic records book that keeps a public record of all transactions processed in full transparency without revealing the identity of the transmitter and receiver. In this way, systems that use Blockchain are extremely secure and can become what is needed to provide adequate security for the IoT and to protect user data in that environment.

\section{Prediction on Healthcare Environments}

Most of the studied approaches focus on predicting future patient health conditions. Based on this predictive strategy, applications are able to inform patients, doctors, and family members when bad situations will happen so that preventive measures are taken. In this way, risk situations can be minimized and even avoided depending on the prediction time. However, not only the vital signs are 
important when talking about the health of a patient. People are exposed to various situations that may endanger their health. And besides, one of the most common problems, when someone seeks hospital care, is the precarious situation of emergencies in Brazil.

In this context, one of the possibilities of exploration would be to propose systems capable of predicting external factors that influence the health of patients in hospitals. The goal is to capture information from the environment where the patient is inserted, in order to anticipate problems that may affect him. One possibility would be to analyze the resources that a given hospital has and uses to attend to the public, to identify underutilization or overuse of them and, based on past use, to predict when a given resource will be insufficient to meet the demand. In this way, hospital systems are aware of which features are insufficient, what resources are left over, and what resources are going to become insufficient, can they optimize processes, perhaps by eliminating unnecessary resources, and focusing on acquiring those that really are or will be needed.

\section{CONCLUSION}

The objective of this study was to discuss the main issues regarding the use of Data Prediction combined with IoT applied to healthcare and identify the concepts of technology in this area. Differently of others works, this survey does not address only the use of IoT in the healthcare field, but also the use of IoT combined with Data Prediction in order to anticipate and mitigate problems in this area of study. In this context, it was able to identify and propose a broad taxonomy for the scope of work, and an updated view of challenges and possibilities for future studies in this area. Thus, the main objective was completely fulfilled. However, this survey is limited to the use of IoT and Data Prediction techniques applied to the healthcare area. Furthermore, this work just contemplates articles published in electronic scientific libraries, not analyzing other types of work, such as technical or industrial approaches.

It is expected that the taxonomy proposed in this work can help in the classification of different systems using the Internet of Things concept combined with Data Prediction for solving problems in healthcare, serving as a baseline of studies for the scientific community in general. It is hoped that, with this taxonomy, future approaches will be able to identify gaps in healthcare systems, and show ways for future new approaches in the area, improving the future research potentiality. It is also hoped that this research can help hospital IT teams and researchers to propose systems and approaches that can help treat patients in a more automated way with techniques that can predict health problems and prevent them.

As future work was envisioned the development of a model for controlling processes in a healthcare environment, using the Internet of Things paradigm, to record the use of resources by healthcare environment processes, being able to evaluate and predict when the demand for some resource will exceed the capacity of use of the same resource. Therefore, it would be necessary to define which sensors to use and which places they should be allocated, in order to perform data capture for some time. With a good amount of data, Data Prediction techniques could be applied to identify patterns and predict, with a good degree of confidence, the overuse of some resource. Finally, was expected to implement the system in a real healthcare environment, in order to have real data for a better validation of the proposed model.

\section{ACKNOWLEDGMENT}

This work was partially supported by the following Brazilian agencies: CNPq; FAPERGS; and CAPES. 


\section{REFERENCES}

Akeju, O., Butakov, S., \& Aghili, S. (2018). Main factors and good practices for managing BYOD and IoT risks in a K-12 environment. International Journal of Internet of Things and Cyber-Assurance, 1(1), 22-39. doi:10.1504/IJITCA.2018.090161

Ali, F., Islam, S. R., Kwak, D., Khan, P., Ullah, N., Yoo, S., \& Kwak, K. S. (2018). Type-2 fuzzy ontology-aided recommendation systems for iot-based healthcare. Computer Communications, 119, 138-155. doi:10.1016/j. comcom.2017.10.005

Azimi, I., Anzanpour, A., Rahmani, A. M., Pahikkala, T., Levorato, M., Liljeberg, P., \& Dutt, N. (2017). HiCH: Hierarchical Fog-Assisted Computing Architecture for Healthcare IoT. ACM Transactions on Embedded Computing Systems (TECS), 16(5s), 174:1-174:20. doi:10.1145/3126501

Basanta, H., Huang, Y. P., \& Lee, T. T. (2018). Intuitive IoT-based H2U healthcare system for elderly people. In Proceedings of the 2016 IEEE 13th International Conference on Networking, Sensing, and Control (ICNSC), Mexico City, Mexico (pp. 1-6). IEEE. doi:10.1109/ICNSC.2016.7479018

Bhatia, M., \& Sood, S. K. (2018). A comprehensive health assessment framework to facilitate IoT-assisted smart workouts: A predictive healthcare perspective. Computers in Industry, 92-93, 50-56. doi:10.1016/j. compind.2017.06.009

Bhatia, M., \& Sood, S. K. (2018). Exploring Temporal Analytics in Fog-Cloud Architecture for Smart Office HealthCare. Mobile Networks and Applications. doi:10.1007/s11036-018-0991-5

Chen, J., Chen, H., Wu, Z., Hu, D., \& Pan, J. Z. (2017). Forecasting smog-related health hazard based on social media and physical sensor. Information Systems, 64(Supplement C), 281-291. doi:10.1016/j.is.2016.03.011

Darshan, K. R., \& Anandakumar, K. R. (2015). A comprehensive review on usage of internet of things (iot) in healthcare system. In Proceedings of the 2015 International Conference on Emerging Research in Electronics, Computer Science and Technology (ICERECT) (pp. 132-136). Mandya, India: IEEE. doi:10.1109/ ERECT.2015.7499001

EndNote. (2017). Retrieved from https://endnote.com/

Farahani, B., Firouzi, F., Chang, V., Badaroglu, M., Constant, N., \& Mankodiya, K. (2018). Towards fog-driven iot ehealth: Promises and challenges of IoT in medicine and healthcare. Future Generation Computer Systems, 78(Part 2), 659-676. doi:10.1016/j.future.2017.04.036

Gondalia, A., Dixit, D., Parashar, S., Raghava, V., Sengupta, A., \& Sarobin, V. R. (2018). IoT-based Healthcare Monitoring System for War Soldiers using Machine Learning. Procedia Computer Science, 133, 1005-1013. doi:10.1016/j.procs.2018.07.075

Huang, Y., Zhao, Q., Zhou, Q., \& Jiang, W. (2018). Air Quality Forecast Monitoring and Its Impact on Brain Health Based on Big Data and the Internet of Things. IEEE Access: Practical Innovations, Open Solutions, 6, 78678-78688. doi:10.1109/ACCESS.2018.2885142

Jin, T., Zhang, X., Liu, Y., \& Lei, K. (2017). BlockNDN: A Bitcoin Blockchain Decentralized System over Named Data Networking. In Proceedings of the 2017 Ninth International Conference on Ubiquitous and Future Networks (ICUFN), Milan, Italy (pp. 75-80). IEEE. doi:10.1109/ICUFN.2017.7993751

Jouini, R., Lemlouma, T., Maalaoui, K., \& Saidane, L. A. (2016). Employing grey model forecasting gm(1,1) to historical medical sensor data towards system preventive in smart home e-health for elderly person. In Proceedings of the 2016 International Wireless Communications and Mobile Computing Conference (IWCMC), Paphos, Cyprus (pp. 1086-1091). IEEE. doi:10.1109/IWCMC.2016.7577210

Kan, C., Chen, Y., Leonelli, F., \& Yang, H. (2015). Mobile sensing and network analytics for realizing smart automated systems towards health internet of things. In Proceedings of the 2015 IEEE International Conference on Automation Science and Engineering (CASE), Gothenburg, Sweden (pp. 1072-1077). IEEE. doi:10.1109/ CoASE.2015.7294241

Kang, J. J., Adibi, S., Larkin, H., \& Luan, T. (2015). Predictive data mining for converged internet of things: A Mobile Health perspective. In Proceedings of the 2015 International Telecommunication Networks and Applications Conference (ITNAC), Sydney, Australia (pp. 5-10). IEEE. doi:10.1109/ATNAC.2015.7366781 
Kumar, P. M., Lokesh, S., Varatharajan, R., Babu, G. C., \& Parthasarathy, P. (2018). Cloud and IoT based disease prediction and diagnosis system for healthcare using Fuzzy neural classifier. Future Generation Computer Systems, 86, 527-534. doi:10.1016/j.future.2018.04.036

Kuzuno, H., \& Karam, C. (2017). Blockchain explorer: An analytical process and investigat0ion environment for bitcoin. In Proceedings of the 2017 APWG Symposium on Electronic Crime Research (eCrime), Scottsdale, AZ (pp. 9-16). IEEE. doi:10.1109/ECRIME.2017.7945049

Kwon, O. Y., Shin, S. H., Shin, S. J., \& Kim, W. S. (2010). Design of u-health system with the use of smart phone and sensor network. In Proceedings of the 2010 Proceedings of the 5th International Conference on Ubiquitous Information Technologies and Applications, Sanya, China (pp. 1-6). IEEE. doi:10.1109/ICUT.2010.5677830

Manogaran, G., Varatharajan, R., Lopez, D., Kumar, P. M., Sundarasekar, R., \& Thota, C. (2018). A new architecture of Internet of Things and big data ecosystem for secured smart healthcare monitoring and alerting system. Future Generation Computer Systems, 82, 375-387. doi:10.1016/j.future.2017.10.045

Meharouech, A., Elias, J., \& Mehaoua, A. (2015). Future body-to-body networks for ubiquitous healthcare: a survey, taxonomy and challenges. In Proceedings of the 2015 2nd International Symposium on Future Information and Communication Technologies for Ubiquitous HealthCare (Ubi-HealthTech), Beijing, China (pp. 1-6). IEEE. doi:10.1109/Ubi-HealthTech.2015.7203330

Nakamoto, S. (2008). Bitcoin: A Peer-to-Peer Electronic Cash System. Retrieved from https://bitcoin.org/bitcoin.pdf

Orimaye, S. O., Leong, F. C., Lee, C. H., \& Ng, E. C. H. (2015). Predicting proximity with ambient mobile sensors for non-invasive health diagnostics. In Proceedings of the 2015 IEEE 12th Malaysia International Conference on Communications (MICC), Kuching, Malaysia (pp. 6-11). IEEE. doi:10.1109/ MICC.2015.7725398

Paudel, R., Dunn, K., Eberle, W., \& Chaung, D. (2018). Cognitive Health Prediction on the Elderly Using Sensor Data in Smart Homes. In Proceedings of The Thirty-First International Flairs Conference (FLAIRS-31), Melbourne, FL (pp. 317-322). AAAI.

Pinto, S., Cabral, J., \& Gomes, T. (2017). We-care: An iot-based health care system for elderly people. In Proceedings of the 2017 IEEE International Conference on Industrial Technology (ICIT), Toronto, Canada (pp. 1378-1383). IEEE. doi:10.1109/ICIT.2017.7915565

Robben, S., Englebienne, G., \& Kröse, B. (2017). Delta features from ambient sensor data are good predictors of change in functional health. IEEE Journal of Biomedical and Health Informatics, 21(4), 986-993. doi:10.1109/ JBHI.2016.2593980 PMID:27455530

Roehrs, A., da Costa, C. A., Righi, R. da R., \& de Oliveira, K. S. F. (2017). Personal Health Records: A Systematic Literature Review. Journal of Medical Internet Research, 19(1), e13. doi:10.2196/ jmir.5876 PMID:28062391

Sarhan, Q. I. (2018). Internet of things: A survey of challenges and issues. International Journal of Internet of Things and Cyber-Assurance, 1(1), 40-75. doi:10.1504/IJITCA.2018.090162

Senthilkumar, T., Manikandan, B., Devi, M. R., \& Lokesh, S. (2018). Technologies Enduring in Internet of Medical Things (IoMT) for Smart Healthcare System. International Journal of Scientific Research in Computer Science. Engineering and Information Technology, 3(5), 566-572.

Singh, K. J., \& Kapoor, D. S. (2017). Create your own internet of things: A survey of iot platforms. IEEE Consumer Electronics Magazine, 6(2), 57-68. doi:10.1109/MCE.2016.2640718

Singh, P. (2018). Internet of Things based Health Monitoring System: Opportunities and Challenges. International Journal of Advanced Research in Computer Science, 9(1), 224-228. doi:10.26483/ijarcs.v9i1.5308

Sood, S. K. \& Mahajan, I. (2018). IoT-Fog based Healthcare Framework to Identify and Control Hypertension Attack. IEEE Internet of Things Journal, 1-8. doi:10.1109/JIOT.2018.2871630

Tan, E. T., \& Halim, Z. A. (2018). Health care Monitoring System and Analytics Based on Internet of Things Framework. Journal of the Institution of Electronics and Telecommunication Engineers, 1-8. doi:10.1080/03 772063.2018.1447402 
Thakur, S. S., Abdul, S. S., Chiu, H.Y., Roy, R. B., Huang, P. Yu., Malwade, S., Nursetyo, A. A., \& Li, Y. C. (2018). Artificial-Intelligence-Based Prediction of Clinical Events among Hemodialysis Patients Using NonContact Sensor Data. Sensors, 18(9), 2833:1-2833:16. doi:10.3390/s18092833

Verma, P., Sood, S. K., \& Kalra, S. (2018). Cloud-centric IoT based student healthcare monitoring framework. Journal of Ambient Intelligence and Humanized Computing, 9(5), 1293-1309. doi:10.1007/s12652-017-0520-6

Zamanifar, A., Nazemi, E., \& Vahidi-Asl, M. (2017). Dmp-iot: A distributed movement prediction scheme for IOT health-care applications. Computers \& Electrical Engineering, 58(Supplement C), 310-326. doi:10.1016/j. compeleceng.2016.09.015

Gabriel Souto Fischer received his BSC in Computer Science from the Universidade do Vale do Rio dos Sinos in 2016, and his MSc in Applied Computing from the Universidade do Vale do Rio dos Sinos in 2019. His research interests include internet of things, distributed applications, applications in healthcare, elasticity, and human resources management.

Rodrigo da Rosa Righi received his BSc in Computer Science from Universidade Federal de Santa Maria in 2003, the MSc and PhD in Computer Science from Universidade Federal do Rio Grande do Sul in 2005 and 2009 , respectively, the postdoctorate from Korea Advanced Institute of Science and Technology in 2013. He is currently the Applied Computing Graduate Program coordinator and research professor in Universidade do Vale do Rio dos Sinos. His research interests include Internet of Things, Load Balance and Distributed Applications.

Vinicius Facco Rodrigues received his BSc in Computer Science from Universidade do Vale do Rio dos Sinos in 2012, the MSc in Applied Computing from Universidade do Vale do Rio dos Sinos in 2016. He is currently a PhD student in Applied Computing from Universidade do Vale do Rio dos Sinos. His research interests include Cloud Computing and Sensor Networks.

Cristiano André da Costa received his BSc in Computer Science from Universidade Católica de Pelotas in 1994, the MSc and PhD in Computer Science from Universidade Federal do Rio Grande do Sul in 1997 and 2008 , respectively. He is currently an Applied Computing Graduate Program research professor in Universidade do Vale do Rio dos Sinos. His research interests include Ubiquitous and pervasive computing, mobile computing, context science, distributed systems, cloud computing, Internet of Things, high-performance processing, and applications in healthcare. 